University of Nebraska - Lincoln

DigitalCommons@University of Nebraska - Lincoln

\title{
The Stability and Oxidation Resistance of Iron- and Cobalt-Based Magnetic Nanoparticle Fluids Fabricated by Inert-Gas Condensation
}

\author{
Nguyen H. Hai \\ University of Nebraska - Lincoln \\ Raymond Lemoine \\ University of Nebraska - Lincoln \\ Shaina Remboldt \\ University of Nebraska - Lincoln \\ Michelle A. Strand \\ Southeast Community College- Milford, Milford, NE 68405, U.S.A. \\ Steve Wignall \\ Seward High School, Seward NE, 68434 U.S.A. \\ See next page for additional authors \\ Follow this and additional works at: https://digitalcommons.unl.edu/mrsecfacpubs \\ Part of the Materials Science and Engineering Commons
}

Hai, Nguyen H.; Lemoine, Raymond; Remboldt, Shaina; Strand, Michelle A.; Wignall, Steve; Shield, Jeffrey E.; and Leslie-Pelecky, Diandra, "The Stability and Oxidation Resistance of Iron- and Cobalt-Based Magnetic Nanoparticle Fluids Fabricated by Inert-Gas Condensation" (2005). Faculty Publications: Materials Research Science and Engineering Center. 81.

https://digitalcommons.unl.edu/mrsecfacpubs/81

This Article is brought to you for free and open access by the Materials Research Science and Engineering Center at DigitalCommons@University of Nebraska - Lincoln. It has been accepted for inclusion in Faculty Publications: Materials Research Science and Engineering Center by an authorized administrator of DigitalCommons@University of Nebraska - Lincoln. 


\section{Authors}

Nguyen H. Hai, Raymond Lemoine, Shaina Remboldt, Michelle A. Strand, Steve Wignall, Jeffrey E. Shield, and Diandra Leslie-Pelecky 


\title{
The Stability and Oxidation Resistance of Iron- and Cobalt-Based Magnetic Nanoparticle Fluids Fabricated by Inert-Gas Condensation
}

Nguyen H. Hai ${ }^{1}$, Raymond Lemoine ${ }^{1}$, Shaina Remboldt ${ }^{1}$, Michelle A. Strand ${ }^{2}$, Steve Wignall ${ }^{3}$, Jeffrey E. Shield ${ }^{4}$, and Diandra Leslie-Pelecky ${ }^{1}$

${ }^{1}$ Department of Physics \& Astronomy and Center for Materials Research \& Analysis, University of Nebraska - Lincoln, Lincoln NE 68588-0111, U.S.A.

${ }^{2}$ Southeast Community College- Milford, Milford, NE 68405, U.S.A.

${ }^{3}$ Seward High School, Seward NE, 68434 U.S.A.

${ }^{4}$ Department of Mechanical Engineering and Center for Materials Research \& Analysis, University of Nebraska - Lincoln, Lincoln NE 68588-0656, U.S.A.

\begin{abstract}
Magnetic nanoparticle fluids have numerous biomedical applications, including magnetic imaging, drug delivery, and hyperthermia treatment for cancer. Ideal magnetic nanoparticle fluids have well-separated, biocompatible nanoparticles with a small size distribution that form a stable colloid. We have combined inert-gas condensation, which produces nanoparticles with low polydispersity, with deposition directly into a surfactant-laden fluid to prevent agglomeration. Iron, cobalt, and iron-nitride nanoparticle fluids fabricated using inert-gas condensation have with mean particle sizes from 5-50 nm and remain stable over long periods of time. Iron and cobalt nanoparticles oxidize on exposure to air, with oxidation rates dependent on surfactant type and concentration. Iron-nitride fluids are more oxidation and corrosion resistant, while retaining the same high degree of colloidal stability. Magnetic properties vary depending on the nanoparticle size and material, but can be varied from superparamagnetic to ferromagnetic with coercivities on the order of 1000 Oe. In addition to future biomedical applications, inertgas condensation into fluids offers the opportunity to study interparticle interactions over a broad range of intrinsic materials parameters and interparticle separations.
\end{abstract}

\section{INTRODUCTION}

Magnetic nanoparticle fluids have a wide variety of biomedical applications, including magnetic imaging, sorting, targeting, and hyperthermia [1-3]. The majority of fluids currently used are iron oxides due to their high degree of biocompatibility; however, applications requiring magnetic targeting (such as drug delivery) would benefit greatly from nanoparticle fluids with higher magnetic moments than available from iron oxides. Chemical synthesis and mechanical grinding are common fabrication methods; however, some chemical reactions limit the materials that can be made, and many are restricted to small particle sizes. Mechanical grinding, while able to produce large amounts of material, has the disadvantage of producing large particle-size distributions. Physical-vapor-deposition methods such as inert-gas condensation offer fine control over particle-size distribution, mean particle size, and can form nanoparticles from a variety of different types of materials. 


\section{SAMPLE PREPARATION}

Inert-gas condensation is a process in which an atomic vapor is ejected into a inert gas (often $\mathrm{Ar}$ and/or He) at pressures on the order of $10^{-1}$ torr $[4,5]$. The vapor atoms thermalize via collisions with the inert gas and form uniformly sized clusters. Clusters can be collected on a liquid-nitrogen-cooled coldfinger and compacted to form a solid, or deposited as a film on a substrate with or without a matrix material. Inert-gas condensation can be used to make clusters of virtually any material that can be vaporized by thermal evaporation, e-beam evaporation or sputtering, including ordered magnetic alloys [6,7]. The ultra-high-vacuum-based technique can produce 10-30 mg of magnetic clusters per hour, with a trade-off between amount of clusters produced and the breadth of the particle-size distribution. Reactive sputtering can be used to form oxides and nitrides, which allows fabrication of a broad variety of materials [8].

Magnetic fluids, especially for in vivo applications, must have well-dispersed, separated clusters that remain stable in the fluid. Collecting clusters on a coldfinger inevitably produces some degree of agglomeration. Depositing clusters on a drum rotating into a trough containing a surfactant-laden fluid eliminates agglomeration and produces a well-dispersed magnetic fluid in a single step [9]. Figure 1 shows a schematic illustration of inert-gas condensation into a fluid/surfactant mixture. The vapor atoms (1) collide with inert-gas molecules to form clusters (2) that land on a fluid-coated drum (3). The drum rotates into a cooled reservoir containing oil and surfactant (4). Varying the types of oil and surfactants affects mean particle size and dispersability. Inert-gas-condensed clusters can have mean sizes from $5-50 \mathrm{~nm}$, with the mean particle size controlled by the sputtering pressure, type of inert gas, distance between the gun and the substrate, and the sputtering power.

A turbomolecular or diffusion pump is used to reduce the base pressure to $\sim 10^{-7}$ torr, and to control the inert-gas pressure during deposition. The initial evacuation of the vacuum chamber degases the fluid/surfactant mixture. A shutter in front of the sputter source allows presputtering of the target so that any oxides on the target surface are removed prior to making the magnetic fluid. Octoil ${ }^{\circledR}$ (vapor pressure $=10^{-7}$ torr) or Octoil- $S^{\circledR}$ (vapor pressure $=10^{-8}$ torr) diffusion pump oil is introduced using a load-lock system that allows transfer to and from the vacuum chamber without breaking vacuum or exposing the fluid to air. After sputtering, the fluid is decanted under vacuum into a flask and transferred into an argon-filled glovebox. For biomedical applications, ligand exchange can be used to transfer the nanoparticles into an aqueous-based fluid.

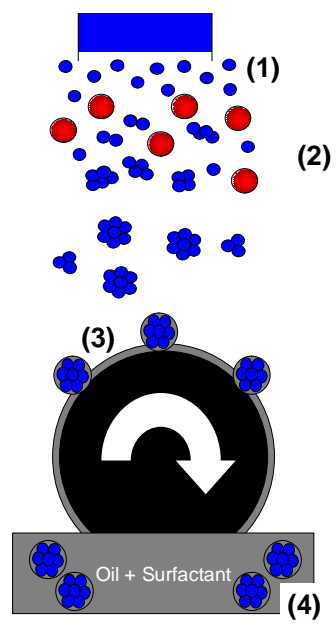

Figure 1. Schematic illustration of cluster formation via inert-gas condensation into a liquid. 
Atomic absorption spectroscopy is used to determine the concentration of metal in the fluids. Structure is determined using a Rigaku D-MAX-B x-ray diffractometer and a JEOL 2000 transmission electron microscope. TEM samples are made by flocculating the fluid using acetone, and separating the nanoparticles from the fluid via centrifugation. Magnetic measurements are made using a SQUID susceptometer and an alternating-gradient force magnetometer. Fluids are sealed in polyethylene bags for measurement.

\section{DATA AND DISCUSSION}

$\mathrm{Fe}, \mathrm{Co}$ and $\mathrm{Fe}_{\mathrm{x}} \mathrm{N}(\mathrm{x}=3,4)$ fluids with particle sizes from $5-50 \mathrm{~nm}$ have been fabricated using inert-gas condensation into a fluid. Transmission Electron Microscopy (TEM) shows that the particles are spherical with narrow size distributions. Figure 2 shows a TEM picture of cobalt nanoparticles with mean particle size $42 \pm 3 \mathrm{~nm}$. The room-temperature magnetic properties of iron and cobalt fluids vary with particle size from superparamagnetic to ferromagnetic. The temperature-dependent magnetization shows irreversibility between the field-cooled and zero-field-cooled susceptibility, and a broad peak at low temperatures [10].

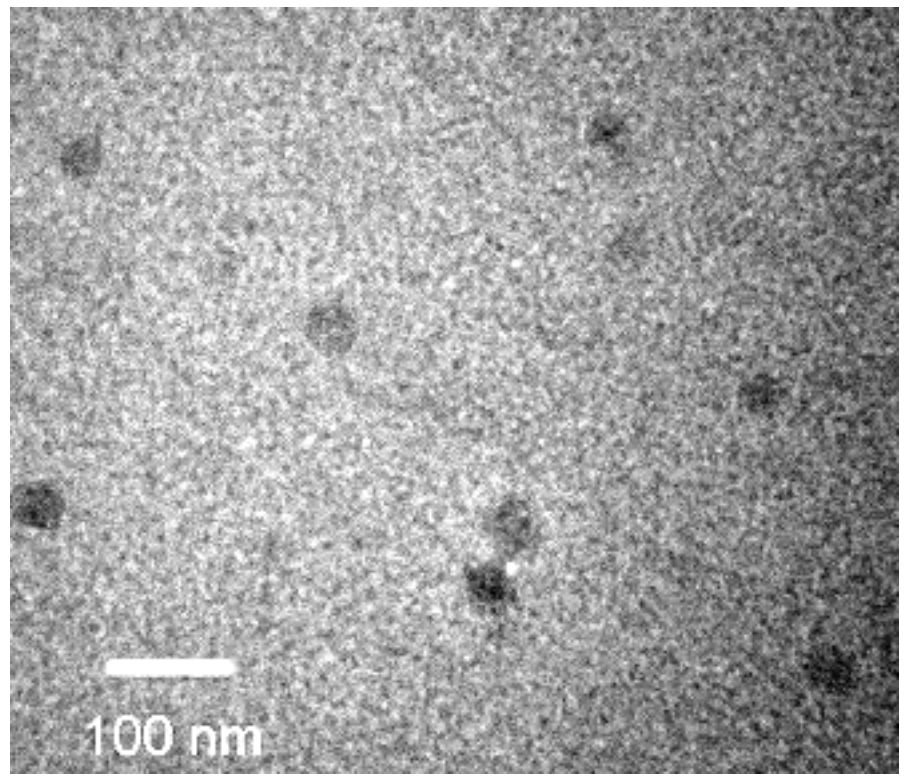

Figure 2: TEM picture of cobalt nanoparticles made in Octoil with 10 vol. \% Brij-92.

Iron nitride has generated significant interest as a high-moment material, including spirited debates over the existence and properties of the $\mathrm{Fe}_{16} \mathrm{~N}_{2}$ phase [11]. Regardless of whether an extraordinarily high-moment phase exists, a number of $\mathrm{Fe}_{1-\mathrm{x}} \mathrm{N}_{\mathrm{x}}$ phases offer significantly higher moments than iron oxides and less potential for oxidation than pure iron. $\mathrm{Fe}_{1-\mathrm{x}} \mathrm{N}_{\mathrm{x}}$ nanoparticles have been fabricated by different techniques, including mechanical alloying, evaporation into liquids, laser pyrolysis, plasma CVD, and chemical synthesis [8,12,13].

We have fabricated $\mathrm{Fe}_{4} \mathrm{~N}$ and $\mathrm{Fe}_{3} \mathrm{~N}$ fluids using reactive sputtering from an iron target. Argon and nitrogen gases are used simultaneously during nanoparticle fabrication, with different phases obtained by varying the argon-nitrogen ratio. Phase determination is made in samples 
sputtered directly onto a substrate to allow x-ray diffraction measurements, and by electron diffraction from flocculated samples in a transmission electron microscope.

$\mathrm{Fe}_{3} \mathrm{~N}$ fluids made in Octoil with 25 vol. \% Korantin-SH surfactant have a mean particle size of $14 \mathrm{~nm}$ and a coercivity on the order of 1000 Oe at room temperature. Figure 3a shows the electron diffraction pattern from a $\mathrm{Fe}_{4} \mathrm{~N}$ sample made in Octoil-S with 20 vol. \% oleic acid as the surfactant and a mean particle size of approximately $10 \mathrm{~nm}$. Figure $3 \mathrm{~b}$ shows the magnetization as a function of field at room temperature for the same $\mathrm{Fe}_{4} \mathrm{~N}$ fluid. Curve 1 (open circles) shows the as-measured data, which includes a diamagnetic background due to the oil, surfactant and the polytheylene bag containing the sample. Curve 2 (solid squares) shows the data after the diamagnetic background has been subtracted.

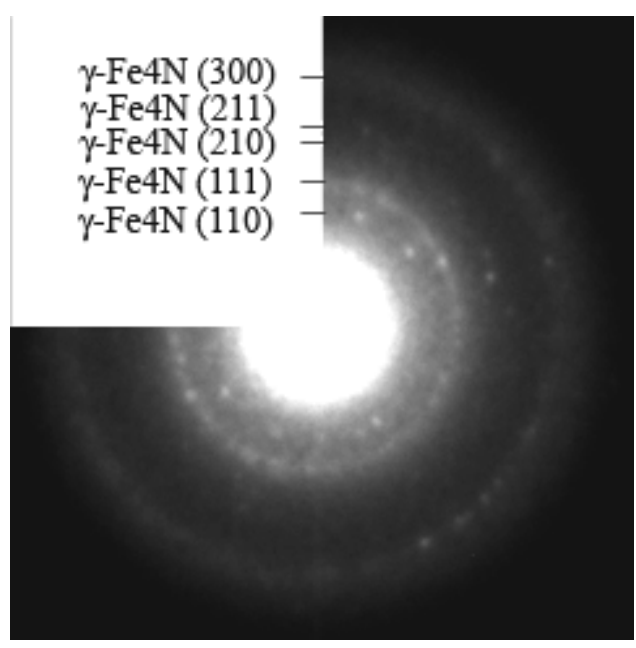

(a)

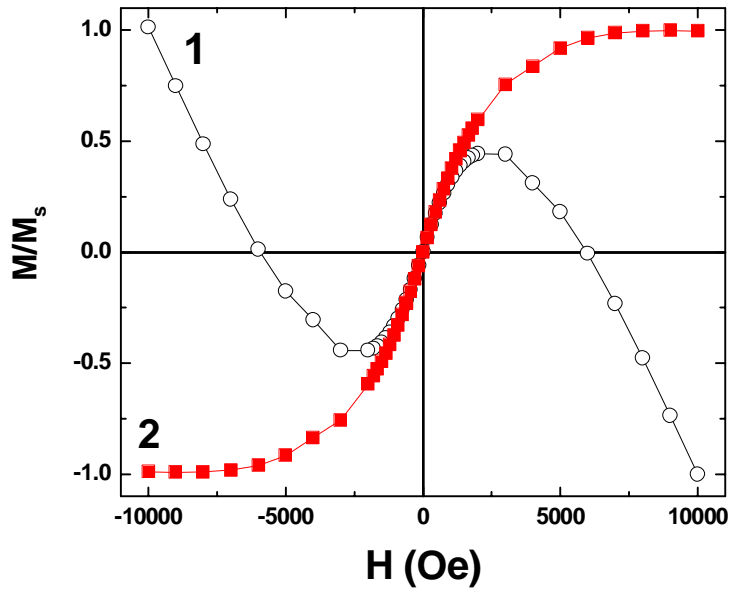

(b)

Figure 3: (a) Electron diffraction pattern for $\mathrm{Fe}_{4} \mathrm{~N}$ magnetic fluid with 10-nm particles. (b) Magnetization as a function of magnetic field for the same $\mathrm{Fe}_{4} \mathrm{~N}$ fluid at room temperature. Curve 1 is the as-measured data, including contributions from the fluid, surfactant and measuring bag, while curve 2 shows the data after this diamagnetic background has been removed.

\section{$\underline{\text { Oxidation, dispersibility and stability }}$}

We have studied a variety of surfactant/fluid combinations to determine their ability to improve dispersibility, stability and oxidation resistance. Fluids studied include Octoil ${ }^{\circledR}$, Octoil$\mathrm{S}^{\circledR}$ and Dow Corning 704, which differ primarily in terms of their viscosity and vapor pressure. The surfactants used span a range of HLB (hydrophilic-lipophilic balance) values and include oleic acid (HLB=1), Brij-92 (HLB=4.9), Span 60 (HLB=4.9), Span 20 (HLB=8.6), Hamposyl-O $(\mathrm{HLB}=9.6)$ and Korantin-SH $(\mathrm{HLB}=9.6)$. Surfactants were studied at concentrations from 1 to 30 vol. $\%$.

The oxidation resistance of iron and cobalt fluids is strongly affected by the surfactants used. The magnetization of iron fluids exposed to air for 15 minutes and then stored under argon is approximately the same as that of fluids that have not been exposed to air; however, leaving an iron fluid exposed to air for 24 hours changes in the fluid from a golden to a dark brown color. Figure $4 \mathrm{a}$ shows the change in saturation magnetization $M_{s}$ as a function of time relative to the magnetization of the same sample immediately after fabrication for an iron fluid made with different volume percentages of the surfactant Brij-92. The mean particle size of the iron 
nanoparticles in all samples was approximately $15 \mathrm{~nm}$ and all were made using Octoil as the base fluid. A significant degradation of magnetization is observed after only two days, with the magnitude of the decrease increasing as the volume fraction of the surfactant decreases. No significant improvement in oxidation resistance is observed for volume fractions greater than $20 \mathrm{vol}$. \% of Brij-92. Figure $3 \mathrm{~b}$ shows that different surfactants have significantly different effects on oxidation. Hamposyl-O at a concentration of 5 vol. $\%$ prevents oxidation better than 20 vol. of \% Brij-92. This likely is due to the difference in chemical reactivity and conformation of the different surfactants. The mean magnetic volume was determined by fitting the magnetization as a function of temperature to Langevin functions weighted by a log-normal distribution of particle sizes. Assuming no change in the anisotropy, a 1.5-nm non-magnetic shell develops over three weeks.

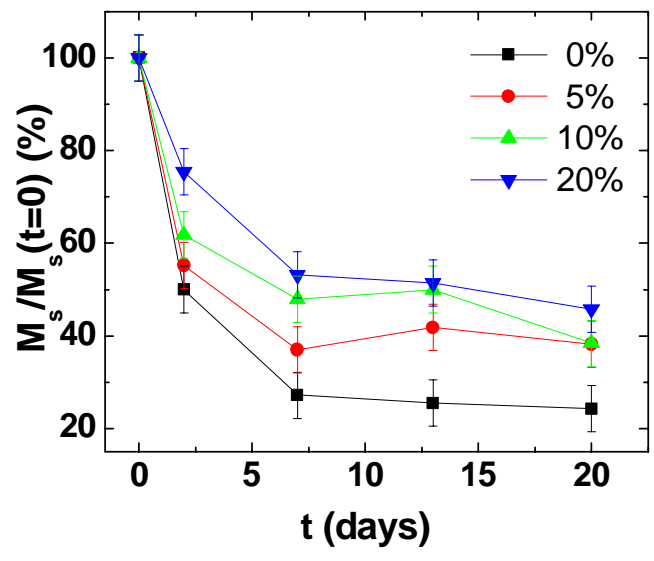

(a)

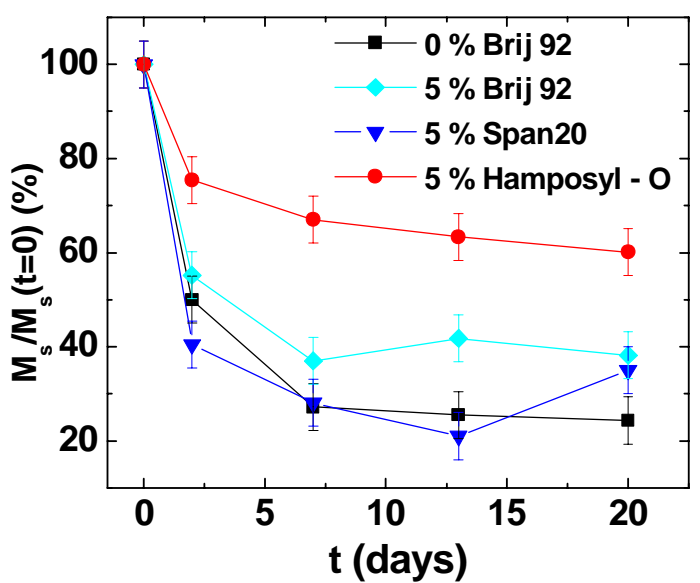

(b)

Figure 4: (a) The change in magnetization of Brij-92-coated iron fluids as a function of time in air. (b) The change in magnetization of iron fluids coated with different surfactants as a function of time in air. The vertical axis in both graphs is the saturation magnetization relative to the value immediately after fabrication.

The behavior of hysteresis loops of cobalt fluids under field cooled (FC) and zero-fieldcooled (ZFC) conditions is consistent with oxidation as the source of the decrease in magnetic properties. Cobalt fluids show minimal changes in the magnetization on the time scale of a week; however, after five months in air, the coercivity at $10 \mathrm{~K}$ for a cobalt fluid with a mean particle size of $42 \mathrm{~nm}$ decreased from 100 Oe to 20 Oe. The hysteresis loop showed a significant shift when measured after field cooling, which is consistent with exchange biasing due to an oxided layer around the nanoparticle core [14].

Since the particle size can be varied easily, controlled oxidation (or nitrogenation) of the surface is one option for passivating iron and cobalt nanoparticles; however, iron-nitride nanoparticle fluids have significantly better oxidation resistance relative to iron nanoparticle fluids. A detailed study of the time-dependence of magnetization of air-exposed iron-nitride nanoparticle fluids is in progress, but there appears to be little change in the magnetic properties of iron-nitride fluids with exposure to air. Iron-nitride fluids also show enhanced corrosion resistance. Atomic absorption spectroscopy (AAS), which is used to determine the concentration of $\mathrm{Fe}$ or $\mathrm{Co}$ present in a nanoparticle fluid, requires dissolving the nanoparticles in acid. Fe and 
Co nanoparticles are dissolved easily by weak hydrochloric acid; however, FeN particles require full-strength nitric acid to be dissolved.

\section{CONCLUSIONS}

We have produced iron, cobalt and iron-nitride magnetic fluids with narrow particle-size distributions using inert-gas condensation directly into a fluid/surfactant mixture. Mean nanoparticle size can be varied from $5-50 \mathrm{~nm}$ depending on deposition conditions, and magnetic properties at room temperature range from superparamagnetic to ferromagnetic with coercivities up to $1000 \mathrm{Oe}$ in $\mathrm{Fe}_{3} \mathrm{~N}$ fluids. Surfactant choice and concentration significantly affect the oxidation resistance of iron and cobalt fluids. Iron nitride fluids display high oxidation and corrosion resistance and a can be made with a broad range of magnetic properties by varying phase and particle size. These results show that inert-gas condensation into fluids is a highly flexible technique with great potential for tailoring magnetic fluids to biomedical needs, as well as creating magnetic fluids for fundamental study of interactions between magnetic nanoparticles.

\section{ACKNOWLEDGEMENTS}

This project was supported by the Nebraska Research Initiative and the MRSEC program of the National Science Foundation (DMR-0213808). We thank D. Schmitter, V. Labhasetwarm, T. Jain, and K. Warren for experimental assistance.

\section{REFERENCES}

1 R.E. Rosenzweig, Ferrohydrodynamics. (Cambridge University Press, 1985).

2 Urs Häfeli, Wolfgang Schütt, Joachim Teller, and Maciej Zborowski, Scientific and Clinical Applications of Magnetic Carriers. (Plenum Press, 1997).

3 Q. A. Pankhurst, J. Connolly, S. K. Jones, and J. Dobson, J. Phys. D 36, R167 (2003).

4 H. Hahn and R. Averback, J. Appl. Phys. 67, 1113 (1990).

5 C.G. Granqvist and R.A. Buhrman, J. Appl. Phys. 47, 220 (1976).

6 S. Stoyanov, Y. Huang, Y. Zhang, V. Skumryev, G. C. Hadjipanayis, and D. Weller, J. Appl. Phys. 93, 7190 (2003).

7 S. Stoyanov, V. Skumryev, Y. Zhang, Y. Huang, G. Hadjipanayis, and J. Nogues, J. Appl. Phys. 93, 7592 (2003).

8 I. Nakatani and T. Furubayashi, J. Magn. Magn. Mater. 85, 11 (1990).

9 Michael Wagener and Bernd Günther, J. Magn. Magn. Mater. 201, 41 (1999).

10 Nguyen H. Hai, Raymond Lemoine, Shaina Rembolt, Michelle Strand, Jeffrey E. Shield, David Schmitter, Robert H. Kraus Jr., Michelle Espy, and Diandra L. Leslie-Pelecky, J. Magn. Magn. Mater. in press (2005).

11 K. H. Jack, Materials Science Forum 325-326, 91 (2000).

12 C. A. Grimes, D. Qian, E. C. Dickey, J. L. Allen, and P. C. Eklund, J. Appl. Phys. 87, 5642 (2000).

13 D. Li, C. J. Choi, B. K. Kim, and Z. D. Zhang, J. Magn. Magn. Mater. 277, 64 (2004).

14 W.H. Meiklejohn and C.P. Bean, Phys. Rev. 102, 1413 (1956). 